\title{
Primeras observaciones sobre el uso de invertebrados y peces marinos en Pachacamac (Perú) en el siglo XV (período Intermedio Tardío)
}

Premières observations sur l'utilisation des invertébrés et poissons marins à Pachacamac au $X V^{e ̀ m e}$ siècle (Intermédiaire récent)

Preliminary observations on the use of marine invertebrates and fish at Pachacamac in the $X V^{\text {th }}$ century (Late Intermediate Period)

Philippe Béarez, Manuel Gorriti y Peter Eeckhout

\section{OpenEdition}

Journals

Edición electrónica

URL: http://journals.openedition.org/bifea/6339

DOI: $10.4000 /$ bifea.6339

ISSN: 2076-5827

Editor

Institut Français d'Études Andines

Edición impresa

Fecha de publicación: 1 abril 2003

Paginación: 51-67

ISSN: 0303-7495

Referencia electrónica

Philippe Béarez, Manuel Gorriti y Peter Eeckhout, « Primeras observaciones sobre el uso de invertebrados y peces marinos en Pachacamac (Perú) en el siglo XV (período Intermedio Tardío) », Bulletin de l'Institut français d'études andines [En línea], 32 (1) | 2003, Publicado el 08 abril 2003, consultado el 08 diciembre 2020. URL : http://journals.openedition.org/bifea/6339; DOI : https:// doi.org/10.4000/bifea.6339

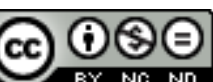

Les contenus du Bulletin de l'Institut français d'études andines sont mis à disposition selon les termes de la licence Creative Commons Attribution - Pas d'Utilisation Commerciale - Pas de Modification 4.0 International. 


\title{
PRIMERAS OBSERVACIONES SOBRE EL USO DE INVERTEBRADOS Y PECES MARINOS EN PACHACAMAC (PERÚ) EN EL SIGLO XV (PERÍODO INTERMEDIO TARDÍO)
}

\author{
Philippe BÉAREZ*, Manuel GORRITI**, Peter EECKHOUT ${ }^{* * *}$
}

\section{Resumen}

El sitio arqueológico de Pachacamac, a pesar de su importancia para la costa central del Perú, es poco conocido a nivel de su economía de subsistencia. Los primeros resultados del estudio de los invertebrados y peces marinos excavados en las unidades 24 y 25 de la pirámide $\mathrm{N}^{\circ}$ III indican que las especies identificadas son habitantes comunes del litoral arenoso actual que se encuentra frente a Pachacamac, Lurín. En referencia al valor nutritivo, los peces constituyen la primera fuente de proteina animal, seguidos por las conchas y los camarones de río. La presencia de Donax obesulus (palabrita) como de Katsuwonus pelamis (barrilete) podría indicar la ocurrencia de un evento El Niño a mediados del siglo XV.

Palabras claves: Pachacamac, Valle de Lurín, costa central, Periodo Intermedio tardio, recursos marinos, malacología, ictiología.

\section{PREMIÈRES OBSERVATIONS SUR L'UTILISATION DES INVERTÉBRÉS ET POISSONS MARINS À PACHACAMAC AU XV ème SIÈCLE (INTERMÉDIAIRE RÉCENT)}

\section{Résumé}

Le site archéologique de Pachacamac, malgré son importance pour la côte centrale du Pérou, est peu connu du point de vue de son économie de subsistance. Les premiers résultats de l'étude des invertébrés et poissons marins mis au jour dans les unités 24 et 25 de la pyramide $\mathrm{N}^{\circ}$ III indiquent que les espèces identifiées sont des habitants communs du littoral sableux actuel proche de Pachacamac, Lurín. Au niveau alimentaire, les poissons constituent la première source de protéine animale suivis par les coquillages et les chevrettes. La présence de Donax obesulus (flion) comme celle de Katsuwonus pelamis (listao) pourrait signaler un événement El Niño vers le milieu du XV ${ }^{\text {ème }}$ siècle.

${ }^{*}$ ESA 8045 CNRS, Muséum national d'histoire naturelle, 55 rue Buffon, 75005 Paris, France. E-mail: bearez@mnhn.fr.

** Museo de Arqueología y Antropología de la Universidad Nacional Mayor de San Marcos, Av. Nicolás de Piérola 1222, Lima 1, Perú. E-mail: gorritimanuel21@hotmail.com.

${ }^{* * *}$ Faculté de Philosophie \& Lettres (CP 175), Université Libre de Bruxelles, Av. F. Roosevelt 50,1050 Bruselas, Bélgica. E-mail: peeckhou@ulb.ac.be. 
Mots clés : Pachacamac, Vallée du Lurín, côte centrale, Intermédiaire récent, ressources marines, malacologie, ichtyologie.

\title{
PRELIMINARY OBSERVATIONS ON THE USE OF MARINE INVERTEBRATES AND FISH AT PACHACAMAC IN THE $\mathrm{XV}^{\text {th }}$ CENTURY (LATE INTERMEDIATE PERIOD)
}

\begin{abstract}
We know little about the subsistence economy of the archaeological site of Pachacamac, despite its importance for the central coast of Peru. The first results of the study of the marine invertebrates and fish excavated in the units 24 and 25 of the pyramid $\mathrm{N}^{\circ}$ III reveal that the species identified in the archaeological record are those usually found in present day sandy coastal areas close to Pachacamac, Valley of Lurin. As food items, fish represent the principal source of animal protein, followed by shellfish from the Pacific and shrimp from the river. The presence of Donax obesulus (donax) as well as of Katsuwonus pelamis (skipjack) may indicate that an El Nino event took place in the middle of the $\mathrm{XV}^{\text {th }}$ century.
\end{abstract}

Key words: Pachacamac, Lurin valley, central coast, Late Intermediate, marine ressources, malacology, ichthyology.

\section{INTRODUCCIÓN}

El sitio de Pachacamac, en la costa central del Perú, constituye uno de los mayores centros arqueológicos de la prehistoria andina tanto por su superficie - más de 500 hectáreas - como por su profundidad temporal: una ocupación permanente de más de 1500 años confirmada desde los inicios de nuestra era hasta la conquista española. Por esta razón ha sido objeto de estudios esencialmente arquitectónicos y funcionales (Bueno Mendoza, 1982; Franco Jordán, 1993a; 1993b; 1998; Jiménez Borja, 1985; Paredes Botoni, 1988; Ühle, 1903) bastante inspirados en datos etnohistóricos. (Rostworowski, 1972;1992) En este lugar se desarrollaron, una tras otra, cuatro culturas prehispánicas (Lima, Huari, Ychsma e Inca), dejando cada una impresionantes vestigios en el centro monumental, entre otros bajo la forma de arquitectura de adobe (Bueno Mendoza, 1982; Shimada, 1991; Ühle, 1903). Considerado durante mucho tiempo únicamente como un centro ceremonial o de culto, los niveles de habitación fueron frecuentemente descuidados. Como esta visión ha sido parcialmente reformulada por uno de nosotros (Eeckhout, 1999a; 1999b; 1999-2000), ahora ya es seguro que la ocupación doméstica del sitio y la subsistencia de residentes han dejado numerosos restos de fauna proveniente del consumo humano. En particular se encuentran numerosos residuos de productos marinos: conchas, quelas de cangrejos y huesos de pescado. La ausencia de información sobre el origen y el uso de estos recursos vivientes por las diferentes categorias sociales durante el período tardío de funcionamiento del sitio de Pachacamac nos ha llevado a estudiar este material. Los primeros resultados de estos estudios se presentan a continuación.

\section{El sitio de Pachacamac}

Pachacamac se sitúa a unos treinta kilómetros al sur de Lima ( $\left.12^{\circ} 14^{\prime} \mathrm{S}-76^{\circ} 53^{\prime} \mathrm{O}\right)$ 
a aproximadamente un kilómetro del Océano Pacífico, sobre la margen derecha del río Lurín, cerca de su desembocadura (Fig. 1). La ocupación permanente del sitio comienza probablemente durante el período Intermedio Temprano (200 a.C. - 550 d.C.). En esa época, los valles bajos del Lurín y del vecino Rimac estaban bajo control de una entidad política estratificada cuyo centro se encontraba en el Valle del Rímac (Earle, 1972; Patterson et al., 1982). La cultura Lima, así se la denomina, se caracteriza por tener un estilo propio de cerámica ( $c f$. Kroeber, 1954; Patterson, 1966; Stumer, 1957) y por la presencia de grandes montículos compuestos por plataformas superpuestas hechas de adobe (Agurto Calvo, 1984; Jijón y Caamaño, 1949; Stumer, 1954, 1958). La mayoría de los autores estiman que el sitio era ya un importante centro religioso en ese período (Bueno Mendoza, 1982; Franco, 1993b, 1993c; Jiménez Borja, 1992). A inicios del Horizonte Medio (ca 550 - 900), Pachacamac sucumbe a la influencia Huari y pasa a ser un centro interregional de difusión de la iconografía y de la ideología religiosa de esta cultura de las tierras meridionales (Menzel, 1964). El período siguiente, el Intermedio Tardío (900 - 1470), es el menos conocido tanto en lo que se refiere a Pachacamac como

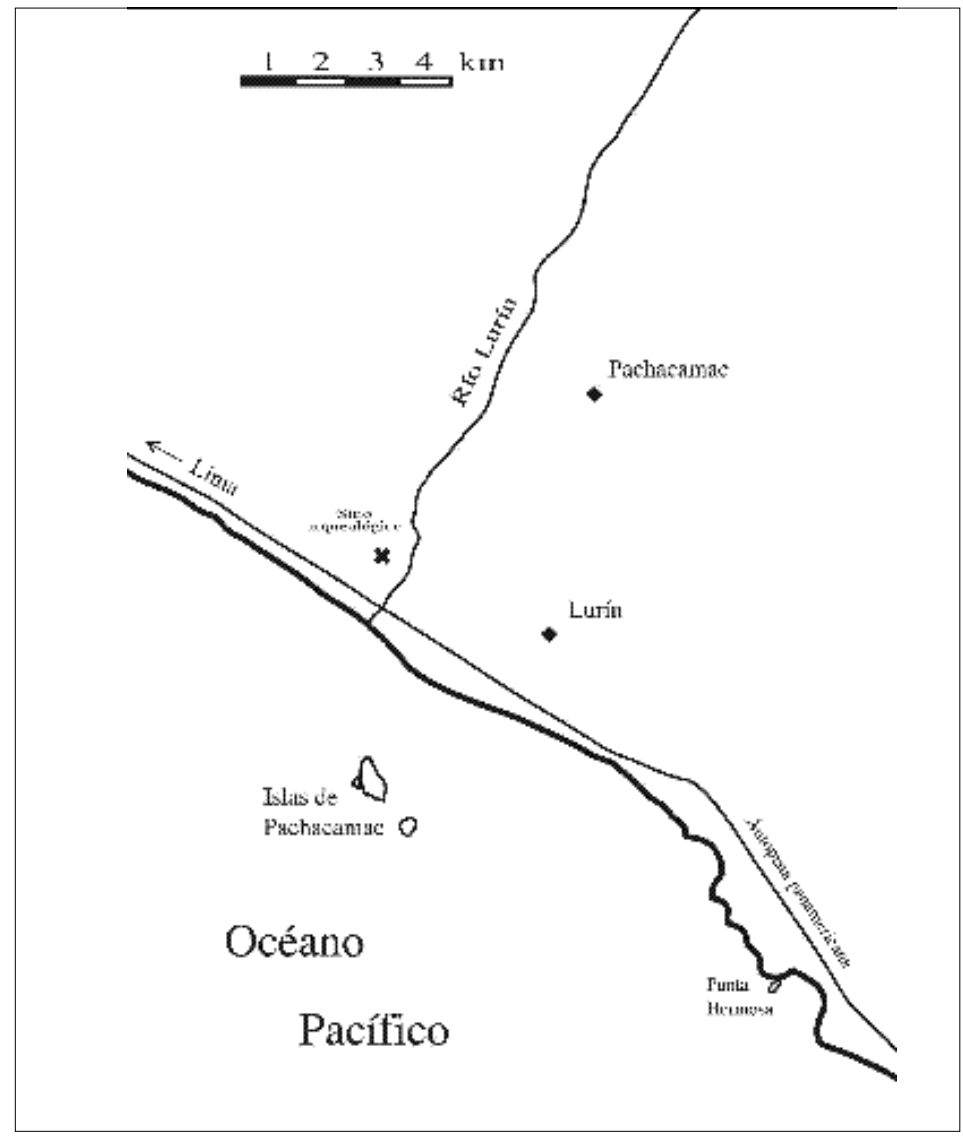

Fig. 1 - Mapa del bajo valle del Lurín.

Fig. 2 - El sitio monumental de Pachacamac (según Ühle, 1903). El complejo 
a la costa central en general (Shimada, 1991). Según las fuentes etnohistóricas, la etnia Ychsma dominaba el valle de Lurín a fines del Período Intermedio Tardío (Rostworowski, 1992). La conquista de la región por Topa Inka Yupanqui hacia 1470 marca el comienzo del Horizonte Tardío y Pachacamac (que se llamaba hasta ese entonces Ychsma) es integrado al imperio inca. Los nuevos dirigentes realizan profundos cambios en el sitio, y construyen particularmente un Templo del Sol y un Acllahuasi (casa de las mujeres escogidas). Cuando los españoles entran a Pachacamac en enero de 1533, lo describen como uno de los establecimientos más vastos y más impresionantes del Perú (Cieza de León, 1994; Estete, 1992; Pizarro, 1872). Sin embargo, algunos años después de la Conquista, se lo abandona completamente (Rowe, 1946).

El sitio cubre una superficie de unas 572 hectáreas de las cuales cerca de un tercio está ocupado por los edificios del sector monumental (Fig. 2). Dos murallas concéntricas lo dividen en dos partes principales. La primera muralla o Muralla Sagrada, encierra el Templo Viejo de Pachacamac, el Templo Pintado, el Templo del Sol, un cementerio importante y los cimientos de una estructura rectangular hoy totalmente destruida. La segunda muralla encierra calles, cementerios, numerosas plazas y explanadas, así como la mayor parte de las pirámides con rampas (ver inmediatamente después), excepto las Pirámides V y VIII, situadas al borde de la zona desértica que separa la segunda muralla de una tercera, la misma que marca el exterior del sitio. Una cuarta muralla se

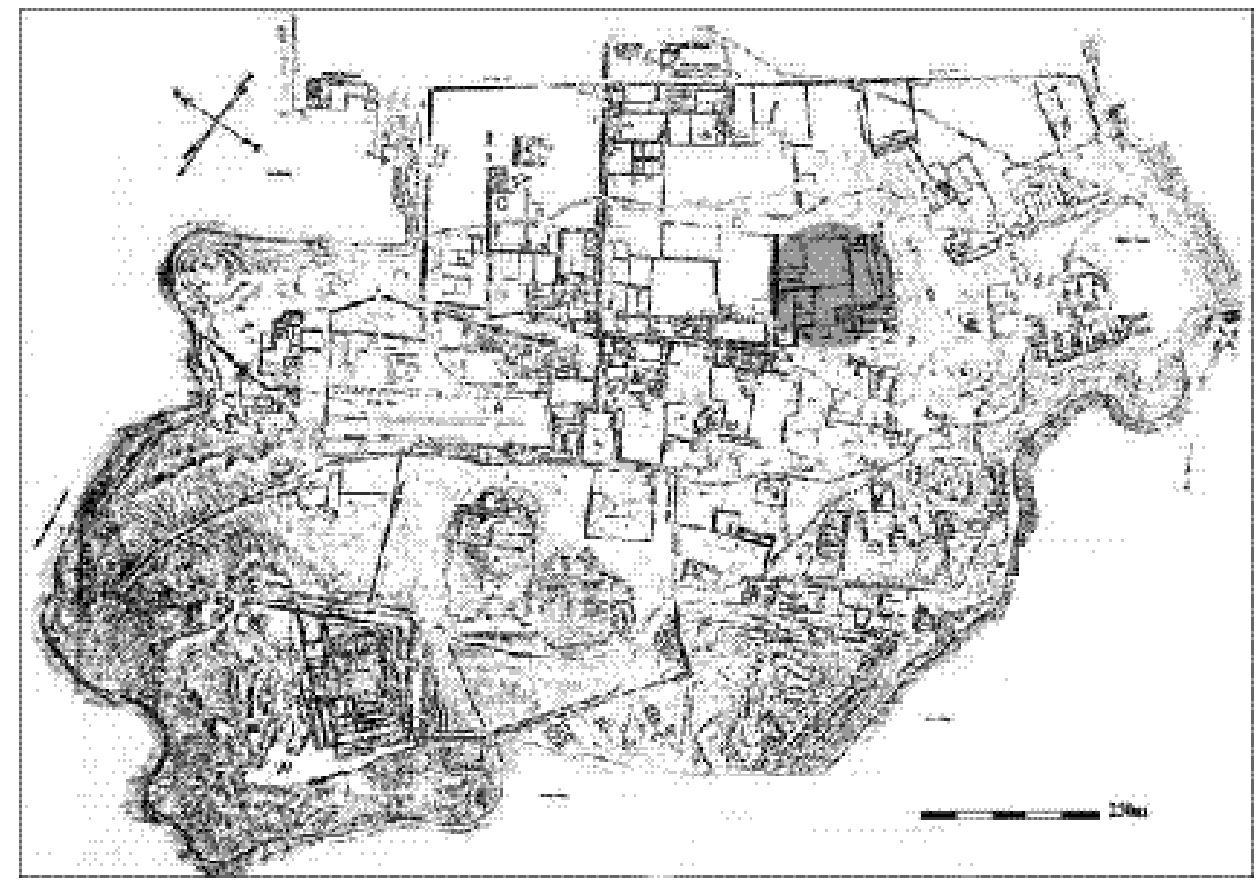

piramidal $\mathrm{N}^{0}$ III está indicado en gris.

Fig. 3 - Plano y reconstitución virtual del complejo piramidal $N^{0}$ III en Pachacamac 
encuentra aproximadamente a un kilómetro de la tercera.

El clima, como en la mayor parte del litoral peruano, es árido y caliente pero aquí, la continuidad desértica esta interrumpida por el caudal continuo del río Lurín y su oasis ribereño. Los alrededores marinos están conformados por amplias playas de arena bañadas por las olas del Océano Pacífico. Frente a la desembocadura del río, a una milla de la costa, el horizonte se entrecorta con la imponente Isla de Cauillaca, la de Pachacamac o Isla San Francisco y algunos islotes rocosos que diversifican los biotopos. Las aguas de esta región son templadas o sea anormalmente frías para estas latitudes debido al fenómeno de upwelling y a la presencia de la corriente fría de Humboldt. Este medio excepcionalmente rico en nutrimentos alberga —o por lo menos albergaba antes del desarrollo de la pesca industrial — una importante biomasa marina representada, en lo que nos interesa a nosotros, por moluscos (machas), crustáceos (muy-muy, cangrejos) y pequeños peces pelágicos (anchovetas, sardinas y jureles).

\section{El proyecto Ychsma y las excavaciones de la Pirámide $N^{0}$ III}

El proyecto Ychsma fue concebido para buscar respuestas a las interrogantes sobre el funcionamiento, el desarrollo y la influencia del sitio de Pachacamac durante el Intermedio Tardío. Se puso el énfasis en el estudio de la arquitectura y de los patrones de asentamiento, particularmente en lo que se refiere a las pirámides con rampa, un tipo de edificio que esta presente en varias decenas de ejemplares en Pachacamac y en diferentes centros de la costa central en el mismo período.

Los resultados de las excavaciones efectuadas en 1993, 1995 y 1999 en Pachacamac y en el valle de Lurín indican que estos edificios estaban ocupados por una pequeña élite que los usaba para ofrecer banquetes y presidir reuniones puntuales a las que asistían numerosos participantes (Eeckhout, 1999c; 1999-2000). De igual modo las pirámides son centros de producción (de textiles, de cerámica), de crianza (de cuyes) y de almacenamiento (de productos agrícolas). En un edificio se han hecho particularmente excavaciones intensivas y extensivas: el complejo piramidal $\mathrm{N}^{\circ}$ III.

Este se encuentra en el noreste del sitio (Fig. 3). El edificio domina el conjunto del sitio (salvo el Templo del Sol) y cubre una superficie de cerca de $16000 \mathrm{~m}^{2}$. El complejo está compuesto de dos pirámides principales (A y B), de una pirámide anexa al noroeste (C), y de dos amplias plazas (II y III) rodeadas de muros. La parte sur del complejo (las pirámides A y B) esta construida sobre una elevación designada como "colina Z" que domina el resto del edificio de 2 a 7 m según los lugares.

El desarrollo del complejo piramidal se divide en siete fases sucesivas desde inicios del siglo XV hasta 1533. Gracias a una serie de 24 muestras analizadas con radiocarbono en 4 laboratorios diferentes, ha sido posible fechar de manera absoluta cada una de esta fases (Michczynski et al., ms).

El material del cual estamos hablando proviene de las unidades 24 y 25 de la pirámide III-B excavadas en 1999. La unidad 24 se presenta como una zanja de cerca de $2 \mathrm{~m}$ de ancho, $26 \mathrm{~m}$ de largo (superficie excavada: $48 \mathrm{~m}^{2}$ ), que atraviesa por el ancho la Plaza V y que se abre al sureste sobre la unidad 25 (Fig. 3). Esta última se presenta en forma de un gran patio cerrado del que han sido excavados unos $72 \mathrm{~m}^{2}$. Estos espacios 

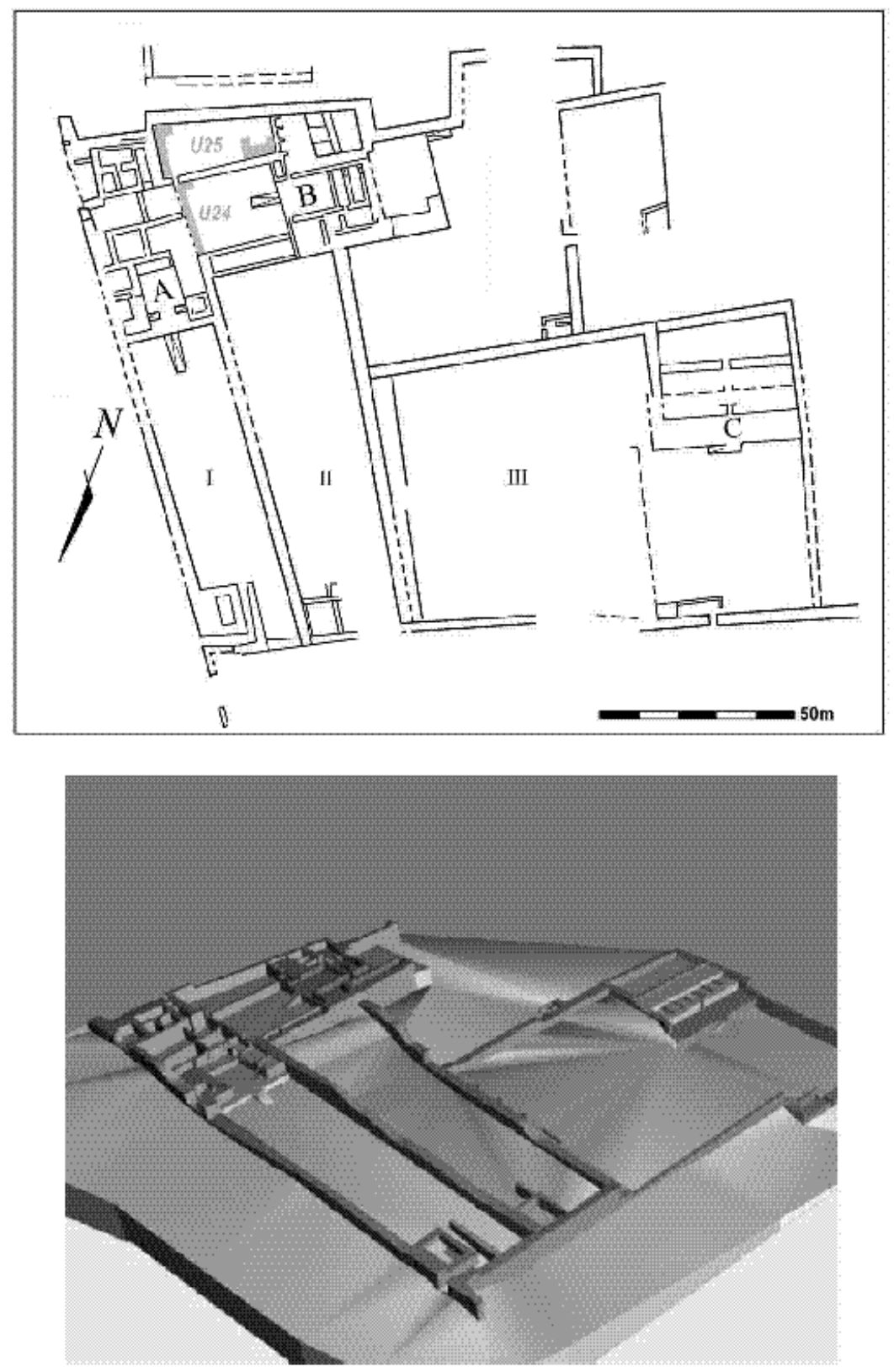

(mostrando las U 24 y 25).

Fig. 4 - Huesos de jurel de la U25. 
se interpretan como lugares de actividad doméstica, particularmente dedicadas a la preparación y al consumo de alimentos por parte de los ocupantes permanentes de la pirámide (en forma cotidiana), pero también por parte de grupos mayores durante reuniones puntuales ( $c f$. Eeckhout \& Farfán, 2001).

Cronológicamente, las diferentes capas de estas unidades fueron puestas en relación con las fases ya mencionadas, lo que permite situarlas en el tiempo con cierta precisión. Así es como sabemos que las capas 24(3), 24(4), 25(2), 25(3) y 25(4) pueden ser fechadas entre 1400 y 1460-1470. Más precisamente, el fechado de la muestra extraída de la capa 24(4) (fragmento de poste intrusivo) permite reajustar el espacio de incertidumbre (cuadro 1) y situar las capas 2 y 3 de esta unidad entre 1431 y 1460 1470 con una probabilidad cercana a la certeza. En el momento del análisis veremos que esta precisión tiene mucha importancia.

\section{MATERIAL Y MÉTODOS}

La totalidad del sedimento de las unidades 24 y 25 fue tamizado con malla de

Cuadro 1 - Fechado de una muestra extraída en la unidad 24, Pirámide $\mathrm{N}^{\circ}$ III.

\begin{tabular}{|c|c|c|c|c|}
\hline U-24-a/b-4 & $\begin{array}{c}\text { Referencia } \\
\text { laboratorio }\end{array}$ & Edad BP & \multicolumn{2}{|c|}{$\begin{array}{c}\text { Edad calibrada } \\
\text { [aC/dC] }\end{array}$} \\
\hline & & & $\begin{array}{c}\text { intervalo de } \\
\text { confianza } 68 \%\end{array}$ & $\begin{array}{c}\text { intervalo de } \\
\text { confianza } 95 \%\end{array}$ \\
\hline $\begin{array}{c}\text { Material: madera } \\
{ }^{13} \mathrm{C}=-27,67 \% 0\end{array}$ & Gd-12270 & \multirow{2}{*}{$410 \pm 35$} & {$[1604 \mathrm{AD}, 1607$} & {$[1575 \mathrm{AD}, 1626$} \\
& & $\mathrm{AD}] \quad 2,56 \%$ & $\mathrm{AD}]$ & $15,54 \%$ \\
& & {$[1439 \mathrm{AD}, 1489$} & {$[1431 \mathrm{AD}, 1521$} \\
& & $\mathrm{AD}] 65,58 \%$ & $\mathrm{AD}]$ & $80,08 \%$ \\
\hline
\end{tabular}

$3 \mathrm{~mm}$. Luego de separar el material óseo, esencialmente de aves y mamíferos, para un análisis posterior, el conjunto de los restos ictiológicos y malacológicos de las dos unidades fue trasladado al laboratorio para sus análisis.

Los restos de pescados como de moluscos fueron identificados por capas y con la ayuda de las colecciones de referencia, osteológica y malacológica, de los autores (P. B. \& M. G.). En la medida de lo posible se buscó la identificación hasta llegar a la especie. Los números mínimos de individuos o NMI fueron calculados sobre la base de tamaño de las piezas, o de su lateralidad (derecha o izquierda), o de su paridad. Por ejemplo, dos otolitos izquierdos y un derecho, de similar tamaño, equivalen a dos pescados; tres otolitos de diferente tamaño equivalen a tres pescados, cada ápice o umbo completo de gasterópodo o bivalvo equivale a un individuo o a su mitad respectivamente, etc.

\section{RESULTADOS}

Presentamos los resultados en forma de cuadros, individualizando cada grupo 
zoológico y cada unidad excavada. No siendo el material muy abundante, la distribución espacial en los metros cuadrados no ha sido estudiada, y sólo se detallan las capas dentro de las unidades (ver Anexo). Las principales especies presentes, en lo que se refiere a moluscos y pescados (Fig. 4), aparecen en el cuadro 2. Los crustáceos están poco representados; sólo se encontraron 16 restos entre los cuales es notable la presencia de 7 fragmentos de camarón de río (Cryphiops caementarius) en la unidad 25. En esta se puede notar también la presencia de algunos gasterópodos terrestres de la familia Bulimulidae, de los géneros Bostrix (1) y Scutalus (6). Estas especies probablemente no fueron consumidas pero están en calidad de intrusivas en el contexto.

Los presentes resultados son esencialmente de naturaleza cualitativa; las dos

\section{Cuadro 2 - Abundancia absoluta y relativa en números de restos (NR) y en NMI de moluscos y pescados en las unidades 24 y 25.}

\begin{tabular}{|l|cccc|cccc|}
\hline & \multicolumn{4}{|c|}{ Unidad 24 } & \multicolumn{5}{c|}{ Unidad 25 } \\
\hline Taxa & NR & $\mathbf{\%}$ & NMI & $\mathbf{\%}$ & NR & \% & NMI & \% \\
\hline Donax obesulus & 478 & 22,6 & 229 & 39,3 & 213 & 7,2 & 103 & 12,3 \\
Mesodesma donacium & 931 & 44,0 & 108 & 18,6 & 1411 & 47,7 & 250 & 29,9 \\
Aulacomya ater & 315 & 14,9 & 88 & 15,1 & 580 & 19,6 & 175 & 20,9 \\
Semimytilus algosus & 176 & 8,3 & 62 & 10,7 & 315 & 10,7 & 117 & 14,0 \\
Diversos & 214 & 10,2 & 95 & 16,3 & 438 & 14,8 & 191 & 23,4 \\
Total Mollusca & $\mathbf{2 1 1 4}$ & 100 & $\mathbf{5 8 2}$ & 100 & $\mathbf{2 9 5 7}$ & 100 & $\mathbf{8 3 6}$ & 100 \\
Trachurus murphyi & 33 & 32,4 & 7 & 20,0 & 127 & 34,4 & 15 & 23,4 \\
Sardinops sagax & 12 & 11,8 & 3 & 8,6 & 163 & 44,2 & 11 & 17,2 \\
Engraulis ringens & 20 & 19,6 & 4 & 11,4 & 16 & 4,3 & 2 & 3,1 \\
Sciaena deliciosa & 8 & 7,8 & 4 & 11,4 & 11 & 3,0 & 6 & 9,4 \\
Scomber japonicus & 10 & 9,8 & 3 & 8,6 & 5 & 1,4 & 3 & 4,7 \\
Diversos & 19 & 18,6 & 14 & 40,0 & 47 & 12,7 & 27 & 42,2 \\
Total Chrondrichthyes & & & & & & & & \\
+ Teleostei & $\mathbf{1 0 2}$ & 100 & $\mathbf{3 5}$ & 100 & $\mathbf{3 6 9}$ & 100 & $\mathbf{6 4}$ & 100 \\
\hline
\end{tabular}

unidades tienen superficies diferentes y las cuatro capas grosores diferentes y variables dentro de una misma unidad, lo que hace difícil la interpretación cuantitativa. A grosso modo, siendo las capas de la unidad 24 mas gruesas y la superficie excavada menor que en la unidad 25, se puede considerar que los volúmenes de sedimentos tamizados en las dos unidades son de un tamaño similar. La unidad 25 es notoriamente más rica que la 24, lo que parece lógico en la medida en que la primera es una sala que ha podido albergar una actividad doméstica, mientras que la segunda es un lugar de paso, un pasadizo. La única excepción notoria es la abundancia particular del bivalvo Donax obesulus ("palabrita") en la unidad 24, particularmente en la capa 3.

Desde un punto de vista cualitativo hay pocas diferencias entre las dos unidades y se observa que en los dos casos, las principales especies identificadas pertenecen a biotopos marinos bastante definidos: las playas de arena para los moluscos y el mar 


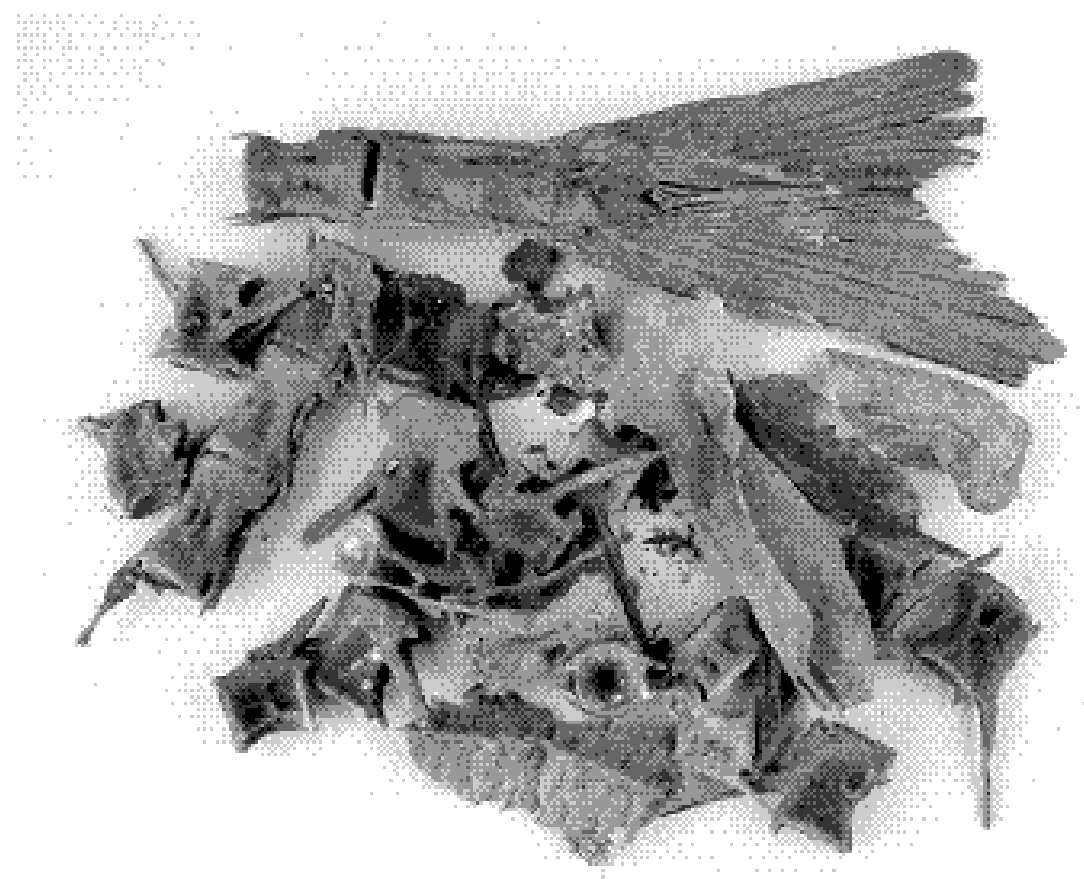

abierto (zona pelágica nerítica) para los peces. Entre las especies secundarias (ver Anexo) se encuentran algunos habitantes de zonas rocosas, como los Muricidae, pero en número muy reducido, y sobre todo recordaremos la muy escasa representación de los Fissurelidae ("lapas").

\section{DISCUSIÓN}

El espectro fáunico tal como aparece luego de un análisis fino de los restos testáceos y óseos es notoriamente representativo del medio ambiente marino inmediato a Pachacamac: grandes playas de arena con un habitat rocoso esencialmente presente en las islas costeras cercanas. Polinices sp., Donax obesulus, Mulinia edulis y Mesodesma donacium son características de las playas de arena bañadas por el océano y se pescan a pie en muy poca agua: las cuatro representan $60,8 \%$ de los restos de moluscos. Los chitones, gasterópodos y mitílidos están enfeudados en los substratos rocosos pero, a pesar de su diversidad, aquí son minoritarios. Observemos que Crepipatella sp. esta frecuentemente asociada con el choro Aulacomya ater y podría haber llegado hasta allí asida a este último, por consiguiente no haber sido objeto de recojo voluntario ni, tal vez, de consumo alimenticio. La presencia de algunos choros grandes o "choro zapato" (Choromytilus chorus), que actualmente viven a partir de cuatro metros de profundidad y sólo en el sur del Perú, plantea el problema recurrente de la explicación de su ocurrencia en los sitios arqueológicos de la costa central o incluso en la costa sur. 
¿Cómo fueron recolectados y por qué y cuándo desaparecieron de casi todo el litoral peruano? La pregunta se mantiene y su respuesta exigirá un estudio detallado de la ecología de esta especie.

Trachurus murphyi (jurel), Sardinops sagax (sardina), Engraulis ringens (anchoveta), Sarda chiliensis (bonito) y Scomberjaponicus (caballa) son peces pelágicos costeños que se encuentran frente a las playas, manteniéndose generalmente detrás de la barrera de las olas: pueden ser pescados mediante redes o para algunos mediante pequeños anzuelos. A las corvinas y lornas, Cilus gilberti, Sciaena wieneri, Sciaena deliciosa, y al lenguado (Paralichthys adspersus) les gustan las aguas turbulentas de las playas, delante de las olas, donde vienen a cazar "muy-muy" (Emerita analoga, crustáceo) y peces pequeños: allí se los puede pescar con redes o anzuelos, incluso con arpones de punta suelta en el caso de peces grandes. Las chitas (Anisotremus scapularis), trambollos (Labrisomus philippii) y cabrillas (Paralabrax humeralis) viven típicamente en los fondos rocosos y se pescan mas bien con anzuelos.

De este análisis se concluye que tanto las orillas de las playas como el alta mar constituían el medio de pesca privilegiado pero que a la vez se practicaba una búsqueda de los recursos en las rocas y en los fondos rocosos de las islas vecinas. Por otro lado, la presencia de algunos restos de "camarón de río" (Cryphiops caementarius) no es nada sorprendente en la medida que el cercano río Lurín debía albergar en esa época una población explotable de esta especie.

El eclectismo del consumo, reflejado en la gran variedad de taxa, podría explicarse como una forma de tributo entregado a los consumidores en la pirámide, por parte de pescadores-recolectores que laboraban en varias zonas. Las fuentes etnohistóricas del siglo XVI señalan en este sentido que los pescadores de Pachacamac, especializados únicamente en esta actividad, ejercían su arte en el litoral de Maranga, o sea Lima, a unos $30 \mathrm{~km}$ al norte de su curacazgo de origen (1), lo que hace suponer que a semejanza de los agricultores y criadores, los pescadores de recursos marinos eran beneficiarios de una especie de territorialidad ampliada, y de derecho de pesca en diferentes lugares, seleccionados seguramente en función de sus particulares recursos (cf. Rostworowski, 1981: 85). Por otro lado, dentro de la pirámide (Plaza V, cerca de la U24) se encontró la mayor diversidad de osamenta de animales usados con fines alimenticios, sobre todo cérvidos, pequeños mamíferos, diferentes camélidos y tal vez perros. Existe un contraste total con lo que se observa en las cabañas del común de la gente, hacia la parte baja de la pirámide, donde hay pocos restos de mamíferos grandes, por no decir nada, y muy poca diversidad (Eeckhout, 1999a: 370-72). Así pues, parece que los ocupantes de la pirámide, dado su status social más alto, tenían acceso a un abanico más amplio de alimentos que los pobladores. Esto se verifica igualmente cuando se compara el estado de dentadura de los individuos enterrados en las pirámides - generalmente muy bueno-y de aquellos enterrados en los cementerios - generalmente deplorable - (Eeckhout, 1998). El acceso a una mayor variedad de productos alimenticios (en este caso tanto

(1) En el Horizonte Tardío, uno de los cuatro linajes tributarios del cacicazgo Ychsma, el linaje de los Quilcaycuna, se componía de pescadores especializados establecidos en el litoral de la margen izquierda del río Lurín (Rostworowski, 1978: 93; 1992: 93-95). 
de mar como de río) podría pues constituir una característica del acceso al recurso de las élites, reflejado en cierta medida en el registro arqueológico. Sobre este tema es importante precisar que ningún artefacto que tenga relación con la extracción de los recursos marinos (redes, anzuelos, trampas, puntas de arpones, restos de embarcaciones, etc.) ha sido encontrado hasta hoy en las excavaciones hechas en Pachacamac, mientras que sí se han encontrado herramientas e infraestructuras destinadas al tejido o a la cerámica, por ejemplo.

En lo que concierne a las biomasas y a las cantidades de carne fresca disponibles para el consumo, el alto número de moluscos en relación a los pescados no debe llevar a falsas interpretaciones. En efecto, una macha (Mesodesma donacium) de tamaño promedio $(7 \mathrm{a} 8 \mathrm{~cm}$ ) proporciona tan sólo $15 \mathrm{~g}$ de materia fresca orgánica consumible mientras que un simple jurel (Trachurus murphyi) de $500 \mathrm{~g}$ proporciona $256 \mathrm{~g}$ de filete (IMARPE / ITP 1996). En el caso presente, el tamaño promedio de los jureles puede ser evaluado en aproximadamente $1 \mathrm{~kg}$, lo que significa que cada individuo equivale a $34(512 / 15=34)$ machas! Notemos que el pescado más grande que se ha identificado es un robalo (Sciaena wieneri) cuyo peso se estima en $7 \mathrm{~kg}$ : el pescado representa pues la primera fuente de proteínas animales de origen marino.

La presencia de un depósito importante de Donax obesulus en la capa 3 de la unidad 24 no es altamente significativa en la medida en que esta especie está también presente, en diferentes grados, en las 4 capas de las dos unidades estudiadas. Este pequeño bivalvo de playas arenosas es considerado por algunos autores (Rollins et al., 1990) como un indicador de aguas calientes y partiendo de ahí, como indicador biológico del fenómeno ENSO (El Niño - Southern Oscillation). Por otra parte, su identificación dentro del material malacológico del sitio arcaico "El Anillo", cerca de Ilo (Sandweiss et al., 1989) ha contribuido, con otros datos del norte del Perú, a la emisión por esos autores (Sandweiss et al., 1996; Sandweiss et al., 2001) de una hipótesis de un recalentamiento global del Pacífico peruano en esa época. Aunque esta posición no sea compartida por todos los arqueólogos y paleoclimatólogos (Díaz \& Ortlieb, 1993), es seguro que en condiciones oceanográficas "normales" — no El Niño_- las "palabritas" no están significativamente presentes en el litoral meridional o central del Perú. El hecho de encontrarlas en Pachacamac denota por lo menos una actividad pesquera de verano y probablemente en un período de penetración de aguas calientes. Este acontecimiento esta corroborado por la presencia en la misma capa 3 de la unidad 24 de una vértebra de bonito o "barrilete" (Katsuwonus pelamis), especie de afinidad tropical. Finalmente, se puede notar en esta misma capa un número reducido de machas, afectadas clásicamente por los fenómenos ENSO, y una ausencia de especímenes de Mulinia edulis, el mismo que es en verdad escaso en otras capas. En efecto, esta última es una especie de agua fría, frecuente en Chile, pero paradójicamente era común en los depósitos arcaicos del litoral central del Perú (L. Ortlieb y V. Mogollón, comunicación personal, 2001). Igualmente, la anchoveta, pez de agua fría asociado al ecosistema de la Corriente de Humboldt, está ausente en las capas 3 y 4 de las unidades 24 y 25 .

Estos escasos índices del advenimiento de un fenómeno ENSO hacia mediados de siglo XV (1430 - 1470) podrían sin embargo ser cercanos al muy fuerte Niño descrito por Wells (1987) en el caso del norte peruano y por Villalba (1994) en el caso del 
centro-sur chileno. El primer autor se basa en el estudio de sedimentos fluviales y fecha el acontecimiento en $1460 \pm 20$; el segundo se basa en los registros dendrocronológicos y glaciales de los Andes chilenos y da la fecha precisa de 1468-1469. Dentro de este marco, la transición hacia un episodio frío moderado (La Niña) - señalado por Villalba (1994) para 1470-1471 - que conduce a la eliminación de las especies de aguas calientes y a la lenta recolonización de las especies de aguas frías, particularmente de las machas que toman muchos años en volver a colonizar el medio luego de un fuerte Niño (P. B., obs. pers.; Sandweiss et al., 2001: 604) podría corresponder a la época de colocación de las capas 24(3) y 24(2).

Si los datos arqueozoológicos presentados aquí revelan la manifestación de un "El Niño", este se habría desarrollado entre 1430 y 1470 y podria concordar con los otros registros paleoclimáticos del litoral Pacífico ( Wells, 1987; Villalba, 1994).

Para corroborar o invalidar la eventual ocurrencia de uno o varios cambios climáticos durante el Intermedio Tardío era igualmente interesante comparar nuestros resultados con los obtenidos en el sitio contemporáneo de Lo Demás, situado cerca de Chincha, al sur de Pachacamac (Sandweiss, 1992). La composición de la fauna marina de ambos sitios es muy parecida, tanto a nivel de los pescados como de los moluscos. En el caso de los primeros, en los dos yacimientos predominan las sardinas y las anchovetas, en el caso de los segundos, entre las cuatro especies principales (sobre la base de los NMI), tres son semejantes (pero con rangos diferentes) y la diferencia más notable radica en la importancia, en Lo Demás, de una especie prácticamente ausente en Pachacamac: Prisogaster niger (cf. cuadro anexado y Sandweiss, 1992: cuadro 27). Este gasterópodo que vive en zonas rocosas intertidales, y que prefiere las aguas frías de la Corriente de Humboldt ocupa en efecto la tercera posición en el conjunto del sitio Lo Demás. La otra diferencia notoria es la abundancia de Mulinia edulis, de la cual ya hemos mencionado su afinidad por las aguas frías, al menos en la actualidad. Al no disponer de los datos del análisis estratigráfico detallado de Lo Demás (Sandweiss, 1989), es difícil conocer las variaciones de frecuencia de los principales moluscos en los niveles que corresponden al Intermedio Tardío, en particular para el par Mesodesma / Donax. Sucede lo mismo con la distribución estratigráfica de las anchovetas. En estas condiciones, incluso si Sandweiss (1992: 105) tiene sospechas de una modificación pasajera del clima, tipo ENSO, hacen falta argumentos para abundar en un sentido o en otro.

\section{CONCLUSIÓN}

El presente ensayo constituye una primicia en el sentido en que hasta la fecha ningún estudio detallado de los recursos marinos en Pachacamac había sido publicado sobre la base de material excavado, salvo algunas consideraciones generales obtenidas sólo de la identificación de registros malacológicos (Eeckhout 1999 a:373-79, Rodríguez de Sandweiss, 1998). Evidentemente, los resultados obtenidos deben ser relativizados en razón del pequeño tamaño de la muestra analizada, pero de todos modos son bastantes instructivos en dos puntos esenciales:

n El eclectismo del consumo, que más allá de mostrar los hábitos alimenticios refleja tal vez algunos aspectos de la organización social y económica de esa época 
(acceso a zonas diversificadas de explotación de recursos; diferenciación social de los hábitos alimenticios) de los que se perciben numerosas reminiscencias en las crónicas de la época colonial.

nConfirmación del impacto, hoy reconocido, de los fenómenos climáticos mayores sobre la fauna marina, pero sobre todo la remarcable facultad de adaptación de las poblaciones humanas afectadas. Efectivamente, parece que los pescadores Ychsma no se dejaron vencer por los cambios que producía en su cotidianidad un eventual ENSO, sino que por el contrario se adaptaron inmediatamente pescando otras especies que sin duda conocían menos bien.

Finalmente, es evidente que los datos aquí presentados son preliminares y que el estudio de los recursos marinos debe ser continuado, sobre todo para verificar o invalidar los índices biológicos de un Niño excepcional durante el siglo XV en la costa central peruana. Además, el resto del material faunico y vegetal debe también ser estudiado, no sólo en el término de identificación taxonómica (lo que ya se ha hecho en parte) sino en términos cuantitativos para poder colocar en perspectiva el conjunto de los datos y elaborar un cuadro exhaustivo de la dieta y de los hábitos alimenticios de los habitantes de Pachacamac durante el Período Intermedio Tardío.

\section{Agradecimientos}

Agradecemos al Instituto Nacional de Cultura del Perú por habernos autorizado a hacer excavaciones en Pachacamac. La campaña 1999 fue financiada por el Fonds de la Recherche Fondamentale Collective (Bélgica) y la Facultad de Filosofía y Letras de la Universidad Libre de Bruselas. El análisis malacológico se financió gracias a la ayuda del Committee for Research and Exploration de la National Geographic Society (Washington). Por sus valiosos comentarios agradecemos a Luc Ortlieb, Valentin Mogollón, Daniel Sandweiss y Elizabeth Reitz.

\section{Referencias citadas}

AGURTO CAlvo, S., 1984 - Lima Prehispánica; Lima: Municipalidad de Lima Metropolitana.

BUENO MENDOZA, A., 1982 - El Antiguo Valle de Pachacamac: Espacio, Tiempo y Cultura. Boletín de Lima, 25: 5-27; Lima: Editorial de Los Pinos.

CIEZA DE LEÓN, P., 1994[1551] - Crónica del Perú, Primera Parte; 352p.; Lima: Pontificia Universidad Católica del Perú-Academia Nacional de la Historia.

DÍAZ, A. \& ORTLIEB, L., 1993 - El fenómeno "El Niño" y los moluscos de la costa peruana. Bulletin de l'Institut Français d'Études Andines, 22(1): 159-177.

EARLE, T. K., 1972 - Lurin Valley, Peru: Early Intermediate Period Settlement Development. American Antiquity, 37: 467-77.

EECKHOUT, P., 1998 - Études anthropophysiques et paléopathologiques dans la vallée du Lurín, Côte centrale du Pérou. Ponencia presentada en el marco del Colloque sur la Médecine Traditionnelle dans le Nouveau Monde, Bruxelles: Musée de la Médecine ULB-Erasme. 
EECKHOUT, P., 1999a-Pachacamac durantl'Intermédiaire récent. Étude d'un site monumental préhispanique de la Côte centrale du Pérou, 504p.;Oxford: Hadrian Books Ltd. British Archaeological Reports International Series, 747.

EECKHOUT, P., 1999b - Pirámide con rampa n III, Pachacamac. Nuevos datos, nuevas perspectivas. Bulletin de l'Institut Français d'Études Andines, 28(2): 169-214.

EECKHOUT, P., 1999c - Les sacrifiés de Pampa de las Flores. Contribution archéologique à l'étude du sacrifice humain dans les Andes préhispaniques. Recherches Amérindiennes au Québec, 29: 18-50.

EECKHOUT, P., 1999-2000 - The Palaces of the Lords of Ychsma. An Archaeological Reappraisal of the Function of Pyramids with Ramps at Pachacamac, Central Coast of Peru. Journal of American Archaeology, 17-18-19: 217-54.

EECKHOUT, P. \& FARFÁN, C., 2001 - La Temporada 1999 de Excavaciones Arqueológicas en la Pirámide con Rampa III de Pachacamac, Costa Central del Perú. Ponencia presentada en el marco del XIII Congreso Peruano del Hombre y la Cultura Andina, Lima.

ESTETE, M. de, 1992[1533] - Nouvelles du Pérou, Translated by Angeles Muñoz and Rosine Gars. In: Nouvelles certaines des Isles du Peru, (Isabel de Soto ed.): 44-81; Amiot. Lenganey, Thaon.

FRANCO JORDAN, R., 1993a - Excavaciones en la Pirámide con rampa $n^{\circ} 2$, Pachacamac; Lima: Universidad Nacional Mayor de San Marcos. Unpublished Master Thesis

FRANCO JORDAN, R., 1993b - El centro ceremonial de Pachacamac: nuevas evidencias en el Templo Viejo. Boletín de Lima, 86: 45-62; Lima.

FRANCO JORDAN, R., 1993c - Los dos templos principales de Pachacamac. Breve síntesis. Revista del Museo de Arqueología, 4: 55-77; Trujillo: Universidad Nacional de Trujillo, Facultad de Ciencias Sociales.

FRANCO JORDAN, R., 1998 - La Pirámide con Rampa $n^{\circ} 2$ de Pachacamac. Excavaciones y Nuevas Interpretaciones; Trujillo.

IMARPE / ITP, 1996 - Compendio biológico tecnológico de las principales especies hidrobiológicas comerciales del Perú, 143p.

JIJÓN Y CAAMAÑO, J., 1949 - Maranga, Contribución al Conocimiento de los Aborígenes del Valle del Rímac, Perú; Quito: La Prensa Católica.

JIMÉNEZ BORJA, A., 1985 - Pachacamac. Boletín de Lima, 38: 40-54; Lima.

JIMÉNEZ BORJA, A., 1992 - Las Huacas. Pachacamac, Revista del Museo de la Nacion, 1(1): 125-31; Lima.

KROEBER, A. L., 1954 - Proto-Lima: A Middle Culture of Peru. Fieldiana Anthropology, 44; Chicago: Chicago Natural History Museum.

MENZEL, D., 1964 - Style and Time in the Middle Horizon. Nawpa Pacha, 2: 1-105.

MICHCZYNSKI,A.,EECKHOUT,P.\& PAZDUR,A., en prensa 2002-14Cabsolutechronologyof the Pyramid III and the Dynastic Model of Pachacamac, Peru. Radiocarbon, Vol. 44.

PAREDES BOTONI, P., 1988 - Pachacamac -Pirámide con Rampa n². Boletín de Lima, 55: 41-58. Lima.

PATTERSON, T. C., - 1966 - Pattern and Process in the Early Intermediate Period Pottery of the Central Coast of Peru; Berkeley and Los Angeles: University of California Publications in Anthropology, 3. University of California Press.

PATTERSON, T. C., McCARTHY, J.P. \& DUNN, R.A., 1982 - Polities in the Lurin Valley during the Early Intermediate Period. Nawpa Pacha, 20: 61-82.

PIZARRO, H., 1872[1533] - A Letter of Hernando Pizarro to the Royal Audience of Santo Domingo, November 1533.In: Reports on the Discovery of Peru, III,(ed. C.R. Markham): 111-127; London. Hayklut Society.

RODRÍGUEZ DE SANDWEISS, M., 1998 - Identificación y análisis de material malacológico. 
In: (R ed. Franco Jordan) La Pirámide con Rampa $n^{\circ} 2$ de Pachacamac. Excavaciones y Nuevas Interpretaciones: 76-90; Trujillo.

ROLLINS, H. B., SANDWEISS, D. H. \& ROLLINS, J. C., 1990 - Mollusks and coastal archaeology: a review. In N. Lasca \& J. Donahue (eds.), Archaeological Geology of North America. Geological Society of America, Boulder, Centennial Special Volume $4-$ pp. 467-478.

ROSTWOROWSKI DE DÍEZ CANSECO, M., 1972 - Breve Informe sobre el Señorio de Ychma o Ychima. Arqueología PUC, 13: 37-51; Lima: Instituto Riva-Agüero, Pontificia Universidad Católica del Perú.

ROSTWOROWSKI DE DIEZ CANSECO, M., 1978 - Señorios Indigenos de Lima y Canta. 280p.; Lima: Instituto de Estudios Peruanos.

ROSTWOROWSKI DE DIEZ CANSECO, M., 1981 - Recursos naturales renovelables y pesca. Siglos XVI y XVII; 180p.; Lima: Instituto de Estudios Peruanos.

ROSTWOROWSKI DE DIEZ CANSECO, M., 1992 - Pachacamac y el Señor de los Milagros. Una Trayectoria Milenaria; 214p.; Lima: Instituto de Estudios Peruanos.

ROWE, J. H., 1946 - Inca Culture at the time of the Spanish Conquest. In: Handbook of South American Indians (Vol. II), (ed. Julian H. Steward): 183-330; Washington: Bureau of American Ethnology, Bulletin 143. .

SANDWEISS, D. H., 1989 - The fishermen of Chincha, Peru: an archaeological investigation of late prehispanic coastal specialization. Ph.D. Thesis, Cornell University. 611p.

SANDWEISS, D. H., 1992 - The archaeology of Chincha fishermen: specialization and status in Inka Peru. Bulletin of the Carnegie Museum of Natural History, Pittsburgh, 29: 161p.

SANDWEISS, D. H., MAASCH, K. A., BURGER, R. L., RICHARDSON III, J. B., ROLLINS, H. B. \& CLEMENT, A., 2001 - Variation in Holocene El Niño frequencies: climate records and cultural consequences in ancient Peru; Geology, 29(7): 603-606.

SANDWEISS, D. H., RICHARDSON III, J. B., REITZ, E. J., HSU, J. T. \& FELDMAN, R. A., 1989 - Early maritime adaptations in the Andes : preliminary studies at the Ring Site, Peru. In: Ecology, settlement and history in the Osmore Drainage, Peru (D. Rice, C. Stanish et P. R. Scarr eds.); Oxford: British Archaeological Reports International Series, 545(1): 35-84.

SANDWEISS, D. H., RICHARDSON III, J. B., REITZ, E. J., ROLLINS, H. B. \& MAASCH, K. A., 1996 - Geoarchaeological evidence from Peru for a 5000 years B.P. onset of El Niño. Science, 273: 1531-1533.

SHIMADA, I., 1991 - Pachacamac Archaeology. Retrospect and Prospect. In Pachacamac. A Reprint of the 1903 Edition by Max Uhle. Philadelphia: University of Pennsylvania Press.

STUMER, L., 1954 - Population Centers of the Rimac Valley of Peru. American Antiquity, 20: $130-48$.

STUMER, L., 1957 - Ceramica negra de estilo Maranga. Revista del Museo Nacional, 26: 272-89; Lima.

STUMER, L., 1958 - Contactos foraneos en la arquitectura de la Costa Central. Revista del Museo Nacional, 27: 11-30; Lima.

ÜHLE, M., 1903 - Pachacamac. Report of The William Pepper, M.D., LL.D. Peruvian Expedition of 1896; Philadelphia: The Dpt of Archaeology of the University of Pennsylvania.

VILLALBA, R., 1994 - Fluctuaciones climáticas en latitudes medias de América del Sur durante los últimos 1000 años: sus relaciones con la Oscilación del Sur. Revista Chilena de Historia Natural, 67: 453-461.

WELLS, L. E., 1987 - An alluvial record of El Niño events from northern coastal Peru. Journal of Geophysical Research, 92: 14463-14470. 


\section{ANEXO 1}

Repartición de los invertebrados y peces maricos por capas de las Unidades 24 y 25 de la pirámide N$^{0}$ III de Pachacamac

\begin{tabular}{|c|c|c|c|c|c|c|c|c|c|c|}
\hline \multirow[b]{2}{*}{ Grupo } & \multirow[b]{2}{*}{ Familia } & \multirow[b]{2}{*}{ Especie } & \multicolumn{2}{|c|}{$24(1)$} & \multicolumn{2}{|c|}{$24(2)$} & \multicolumn{2}{|c|}{$24(3)$} & \multicolumn{2}{|c|}{$24(4)$} \\
\hline & & & NR & NMI & NR & NMI & NR & NMI & NR & NMI \\
\hline Crustacea & Balanidae & Balanus sp. & 0 & 0 & 0 & 0 & 0 & 0 & 0 & 0 \\
\hline Crustacea & Chthamalidae & Jhelius sp. & 0 & 0 & 1 & 1 & 0 & 0 & 0 & 0 \\
\hline Crustacea & Hippidae & Emerita analoga & 0 & 0 & 0 & 0 & 0 & 0 & 0 & 0 \\
\hline Crustacea & Palaemonidae & \multirow{2}{*}{\multicolumn{4}{|c|}{ Cryphiops caementarius 0}} & 0 & 0 & 0 & 0 & 0 \\
\hline & & & & & & & & & & \\
\hline Crustacea & Xanthidae & \multirow{3}{*}{ n. i. } & 0 & 0 & 0 & 0 & 1 & 1 & 0 & 0 \\
\hline Crustacea & n. i. & & 0 & 0 & 0 & 0 & 0 & 0 & 0 & 0 \\
\hline \multicolumn{2}{|c|}{ Total Crustacea } & & $\mathbf{0}$ & $\mathbf{0}$ & 1 & 1 & 1 & 1 & $\mathbf{0}$ & $\mathbf{0}$ \\
\hline Polyplacophora & Chitonidae & n. i. & 0 & 0 & 2 & 1 & 0 & 0 & 0 & 0 \\
\hline Gastropoda & Acmaeidae & n. i. & 0 & 0 & 0 & 0 & 0 & 0 & 0 & 0 \\
\hline Gastropoda & Crepidulidae & Crepipatella $s p$. & 24 & 11 & 38 & 18 & 8 & 4 & 0 & 0 \\
\hline Gastropoda & Fissurellidae & Fissurella maxima & 0 & 0 & 0 & 0 & 0 & 0 & 0 & 0 \\
\hline Gastropoda & Muricidae & \multicolumn{2}{|l|}{ Concholepas concholepas 0} & 0 & 4 & 2 & 2 & 1 & 0 & 0 \\
\hline Gastropoda & Muricidae & Thais chocolata & 21 & 8 & 28 & 10 & 6 & 2 & 0 & 0 \\
\hline Gastropoda & Muricidae & Thais haemastoma & 0 & 0 & 0 & 0 & 0 & 0 & 0 & 0 \\
\hline Gastropoda & Muricidae & Thais sp. & 0 & 0 & 9 & 4 & 0 & 0 & 0 & 0 \\
\hline Gastropoda & Muricidae & Xanthochorus buxea & 0 & 0 & 0 & 0 & 0 & 0 & 0 & 0 \\
\hline Gastropoda & Naticidae & Polinices sp. & 2 & 1 & 10 & 5 & 0 & 0 & 0 & 0 \\
\hline Gastropoda & Trochidae & Tegula atra & 0 & 0 & 3 & 1 & 0 & 0 & 0 & 0 \\
\hline Gastropoda & Trochidae & Tegula euryomphalum & 0 & 0 & 0 & 0 & 0 & 0 & 0 & 0 \\
\hline Gastropoda & Trochidae & Tegula sp. & 0 & 0 & 0 & 0 & 0 & 0 & 0 & 0 \\
\hline Gastropoda & Turbinidae & Prisogaster niger & 0 & 0 & 0 & 0 & 0 & 0 & 0 & 0 \\
\hline Bivalvia & Donacidae & Donax obesulus & 68 & 32 & 120 & 56 & 284 & 139 & 6 & 2 \\
\hline Bivalvia & Mactridae & Mulinia edulis & 2 & 1 & 0 & 0 & 0 & 0 & 0 & 0 \\
\hline Bivalvia & Mesodesmatidae & Mesodesma donacium & 359 & 26 & 507 & 65 & 58 & 16 & 7 & 1 \\
\hline Bivalvia & Mytilidae & Aulacomya ater & 84 & 18 & 195 & 61 & 32 & 8 & 4 & 1 \\
\hline Bivalvia & Mytilidae & Choromytilus chorus & 7 & 3 & 3 & 1 & 3 & 1 & 0 & 0 \\
\hline Bivalvia & Mytilidae & Perumytilus purpuratus & 10 & 5 & 20 & 10 & 8 & 4 & 0 & 0 \\
\hline Bivalvia & Mytilidae & Semimytilus algosus & 57 & 17 & 52 & 23 & 64 & 21 & 3 & 1 \\
\hline Bivalvia & Pectinidae & Argopecten purpuratus & 2 & 1 & 2 & 1 & 0 & 0 & 0 & 0 \\
\hline \multicolumn{2}{|c|}{ Total Mollusca } & & 636 & 123 & 993 & 258 & 465 & 196 & 20 & 5 \\
\hline \multicolumn{2}{|l|}{ Chondrichthyes $\mathrm{n}$. } & & 0 & 0 & 0 & 0 & 0 & 0 & 0 & 0 \\
\hline Teleostei & Carangidae & Trachurus murphyi & 0 & 0 & 7 & 4 & 2 & 1 & 24 & 2 \\
\hline Teleostei & Clupeidae & Sardinops sagax & 0 & 0 & 9 & 2 & 3 & 1 & 0 & 0 \\
\hline Teleostei & Engraulidae & Engraulis ringens & 0 & 0 & 20 & 4 & 0 & 0 & 0 & 0 \\
\hline Teleostei & Haemulidae & Anisotremus scapularis & 0 & 0 & 0 & 0 & 0 & 0 & 0 & 0 \\
\hline Teleostei & Haemulidae & Isacia conceptionis & 0 & 0 & 0 & 0 & 0 & 0 & 0 & 0 \\
\hline Teleostei & Labrisomidae & Labrisomus philippii & 0 & 0 & 0 & 0 & 0 & 0 & 0 & 0 \\
\hline Teleostei & Paralichthyidae & Paralichthys adspersus & 1 & 1 & 0 & 0 & 0 & 0 & 0 & 0 \\
\hline Teleostei & Sciaenidae & Cilus gilberti & 1 & 1 & 0 & 0 & 0 & 0 & 0 & 0 \\
\hline Teleostei & Sciaenidae & Cynoscion analis & 0 & 0 & 0 & 0 & 0 & 0 & 1 & 1 \\
\hline Teleostei & Sciaenidae & Paralonchurus peruanus & 0 & 0 & 0 & 0 & 0 & 0 & 0 & 0 \\
\hline Teleostei & Sciaenidae & Sciaena deliciosa & 0 & 0 & 0 & 0 & 2 & 2 & 6 & 2 \\
\hline Teleostei & Sciaenidae & Sciaena wieneri & 0 & 0 & 0 & 0 & 1 & 1 & 0 & 0 \\
\hline Teleostei & Sciaenidae & Stellifer minor & 0 & 0 & 0 & 0 & 0 & 0 & 0 & 0 \\
\hline Teleostei & Scombridae & Katsuwonus pelamis & 0 & 0 & 0 & 0 & 1 & 1 & 0 & 0 \\
\hline Teleostei & Scombridae & Sarda chiliensis & 1 & 1 & 1 & 1 & 0 & 0 & 0 & 0 \\
\hline Teleostei & Scombridae & Scomber japonicus & 0 & 0 & 0 & 0 & 5 & 2 & 5 & 1 \\
\hline Teleostei & Serranidae & Paralabrax humeralis & 1 & 1 & 0 & 0 & 0 & 0 & 1 & 1 \\
\hline Teleostei & n. i. & & 0 & 0 & 1 & 1 & 0 & 0 & 9 & 4 \\
\hline \multicolumn{3}{|c|}{ Total Chondrichthyes } & & & & & & & & \\
\hline
\end{tabular}




\begin{tabular}{|c|c|c|c|c|c|c|c|c|c|c|c|c|c|c|c|c|c|c|c|}
\hline \multicolumn{4}{|c|}{ Total } & \multicolumn{3}{|c|}{$25(1)$} & \multicolumn{2}{|l|}{$25(2)$} & \multicolumn{2}{|l|}{$25(3)$} & \multicolumn{2}{|l|}{$25(4)$} & \multicolumn{2}{|l|}{ Total } & \multicolumn{5}{|c|}{ Gran total } \\
\hline NR & $\%$ & NMI & I $\%$ & NR & NMI & NR & NMI & NR & NMI & NR & NMI & NR & $\%$ & NMI & I $\%$ & NR & $\%$ & NMI & I $\%$ \\
\hline 0 & $0.0 \%$ & 0 & $0.0 \%$ & 1 & 1 & 0 & 0 & 0 & 0 & 0 & 0 & 1 & $4.8 \%$ & 1 & $9.1 \%$ & 1 & $4.3 \%$ & 1 & $7.7 \%$ \\
\hline 1 & $50.0 \%$ & 1 & $50.0 \%$ & 0 & 0 & 0 & 0 & 0 & 0 & 0 & 0 & 0 & $0.0 \%$ & 0 & $0.0 \%$ & 1 & $4.3 \%$ & 1 & $7.7 \%$ \\
\hline 0 & $0.0 \%$ & 0 & $0.0 \%$ & 0 & 0 & 1 & 1 & 0 & 0 & 0 & 0 & 1 & $4.8 \%$ & 1 & $9.1 \%$ & 1 & $4.3 \%$ & 1 & $7.7 \%$ \\
\hline 0 & $0.0 \%$ & 0 & $0.0 \%$ & 0 & 0 & 5 & 2 & 3 & 1 & 1 & 1 & 9 & $42.9 \%$ & 4 & $36.4 \%$ & 9 & $39.1 \%$ & $6 \quad 4$ & $30.8 \%$ \\
\hline 1 & $50.0 \%$ & 1 & $50.0 \%$ & 0 & 0 & 0 & 0 & 0 & 0 & 0 & 0 & 0 & $0.0 \%$ & 0 & $0.0 \%$ & 1 & $4.3 \%$ & 1 & $7.7 \%$ \\
\hline 0 & $0.0 \%$ & 0 & $0.0 \%$ & 0 & 0 & 0 & 0 & 10 & 5 & 0 & 0 & 10 & $47.6 \%$ & 5 & $45.5 \%$ & 10 & $43.5 \%$ & 6 & $38.5 \%$ \\
\hline 2 & 100 & 2 & 100 & 1 & 1 & 6 & 3 & 13 & 6 & 1 & 1 & 21 & 100 & 11 & 100 & 23 & 100 & 13 & 100 \\
\hline 2 & $0.1 \%$ & 1 & $0.2 \%$ & 0 & 0 & 0 & 0 & 0 & 0 & 0 & 0 & 0 & $0.0 \%$ & 0 & $0.0 \%$ & 2 & $0.0 \%$ & 1 & $0.1 \%$ \\
\hline 0 & $0.0 \%$ & 0 & $0.0 \%$ & 0 & 0 & 2 & 1 & 0 & 0 & 0 & 0 & 2 & $0.1 \%$ & 1 & $0.1 \%$ & 2 & $0.0 \%$ & 1 & $0.1 \%$ \\
\hline 70 & $3.3 \%$ & 33 & $5.7 \%$ & 10 & 5 & 56 & 28 & 44 & 21 & 0 & 0 & 110 & $3.7 \%$ & 54 & $6.5 \%$ & 180 & $3.5 \%$ & 87 & $6.1 \%$ \\
\hline 0 & $0.0 \%$ & 0 & $0.0 \%$ & 0 & 0 & 0 & 0 & 4 & 2 & 0 & 0 & 4 & $0.1 \%$ & 2 & $0.2 \%$ & 4 & $0.1 \%$ & 2 & $0.1 \%$ \\
\hline 6 & $0.3 \%$ & 3 & $0.5 \%$ & 14 & 6 & 11 & 3 & 5 & 1 & 0 & 0 & 30 & $1.0 \%$ & 10 & $1.2 \%$ & 36 & $0.7 \%$ & 13 & $0.9 \%$ \\
\hline 55 & $2.6 \%$ & 20 & $3.4 \%$ & 10 & 5 & 32 & 10 & 33 & 11 & 2 & 1 & 77 & $2.6 \%$ & 27 & $3.2 \%$ & 132 & $2.6 \%$ & 47 & $3.3 \%$ \\
\hline 0 & $0.0 \%$ & 0 & $0.0 \%$ & 2 & 1 & 0 & 0 & 0 & 0 & 0 & 0 & 2 & $0.1 \%$ & 1 & $0.1 \%$ & 2 & $0.0 \%$ & 1 & $0.1 \%$ \\
\hline 9 & $0.4 \%$ & 4 & $0.7 \%$ & 7 & 3 & 2 & 1 & 4 & 2 & 3 & 1 & 16 & $0.5 \%$ & 7 & $0.8 \%$ & 25 & $0.5 \%$ & 11 & $0.8 \%$ \\
\hline 0 & $0.0 \%$ & 0 & $0.0 \%$ & 2 & 1 & 0 & 0 & 0 & 0 & 0 & 0 & 2 & $0.1 \%$ & 1 & $0.1 \%$ & 2 & $0.0 \%$ & 1 & $0.1 \%$ \\
\hline 12 & $0.6 \%$ & 6 & $1.0 \%$ & 8 & 4 & 16 & 8 & 10 & 5 & 2 & 1 & 36 & $1.2 \%$ & 18 & $2.2 \%$ & 48 & $0.9 \%$ & 24 & $1.7 \%$ \\
\hline 3 & $0.1 \%$ & 1 & $0.2 \%$ & 0 & 0 & 1 & 1 & 2 & 1 & 0 & 0 & 3 & $0.1 \%$ & 2 & $0.2 \%$ & 6 & $0.1 \%$ & 3 & $0.2 \%$ \\
\hline 0 & $0.0 \%$ & 0 & $0.0 \%$ & 0 & 0 & 2 & 1 & 0 & 0 & 0 & 0 & 2 & $0.1 \%$ & 1 & $0.1 \%$ & 2 & $0.0 \%$ & 1 & $0.1 \%$ \\
\hline 0 & $0.0 \%$ & 0 & $0.0 \%$ & 0 & 0 & 2 & 1 & 2 & 1 & 0 & 0 & 4 & $0.1 \%$ & 2 & $0.2 \%$ & 4 & $0.1 \%$ & 2 & $0.1 \%$ \\
\hline 0 & $0.0 \%$ & 0 & $0.0 \%$ & 0 & 0 & 2 & 1 & 0 & 0 & 0 & 0 & 2 & $0.1 \%$ & 1 & $0.1 \%$ & 2 & $0.0 \%$ & 1 & $0.1 \%$ \\
\hline 478 & $22.6 \%$ & 229 & $39.3 \%$ & 26 & 13 & 55 & 25 & 14 & 7 & 118 & 58 & 213 & $7.2 \%$ & 103 & $12.3 \%$ & 691 & $13.6 \%$ & 332 & $23.4 \%$ \\
\hline 2 & $0.1 \%$ & 1 & $0.2 \%$ & 0 & 0 & 0 & 0 & 2 & 1 & 0 & 0 & 2 & $0.1 \%$ & 1 & $0.1 \%$ & 4 & $0.1 \%$ & 2 & $0.1 \%$ \\
\hline 931 & $44.0 \%$ & 108 & $18.6 \%$ & 256 & 39 & 605 & 120 & 379 & 67 & 171 & 24 & 1411 & $47.7 \%$ & 250 & $29.9 \%$ & 2342 & $46.2 \%$ & 358 & $25.2 \%$ \\
\hline 315 & $14.9 \%$ & 88 & $15.1 \%$ & 71 & 19 & 274 & 79 & 172 & 47 & 63 & 30 & 580 & $19.6 \%$ & 175 & $20.9 \%$ & 895 & $17.6 \%$ & 263 & $18.5 \%$ \\
\hline 13 & $0.6 \%$ & 5 & $0.9 \%$ & 7 & 3 & 17 & 5 & 11 & 4 & 0 & 0 & 35 & $1.2 \%$ & 12 & $1.4 \%$ & 48 & $0.9 \%$ & 17 & $1.2 \%$ \\
\hline 38 & $1.8 \%$ & 19 & $3.3 \%$ & 14 & 7 & 45 & 20 & 44 & 20 & 6 & 3 & 109 & $3.7 \%$ & 50 & $6.0 \%$ & 147 & $2.9 \%$ & 69 & $4.9 \%$ \\
\hline 176 & $8.3 \%$ & 62 & $10.7 \%$ & 95 & 27 & 99 & 40 & 89 & 36 & 32 & 14 & 315 & $10.7 \%$ & 117 & $14.0 \%$ & 491 & $9.7 \%$ & 179 & $12.6 \%$ \\
\hline 4 & $0.2 \%$ & 2 & $0.3 \%$ & 2 & 1 & 0 & 0 & 0 & 0 & 0 & 0 & 2 & $0.1 \%$ & 1 & $0.1 \%$ & 6 & $0.1 \%$ & 3 & $0.2 \%$ \\
\hline 2114 & 100 & 582 & 100 & 524 & 134 & 1221 & 344 & 815 & 226 & 397 & 132 & 2957 & 100 & 836 & 100 & 5071 & 100 & 1418 & 100 \\
\hline 0 & $0.0 \%$ & 0 & $0.0 \%$ & 1 & 1 & 5 & 2 & 0 & 0 & 0 & 0 & 6 & $1.6 \%$ & 3 & $4.7 \%$ & 6 & $1.3 \%$ & 3 & $3.0 \%$ \\
\hline 33 & $32.4 \%$ & 7 & $20.0 \%$ & 2 & 1 & 112 & 11 & 11 & 2 & 2 & 1 & 127 & $34.4 \%$ & 15 & $23.4 \%$ & 160 & $34.0 \%$ & 622 & $22.2 \%$ \\
\hline 12 & $11.8 \%$ & 3 & $8.6 \%$ & 1 & 1 & 153 & 8 & 0 & 0 & 9 & 2 & 163 & $44.2 \%$ & 11 & $17.2 \%$ & 175 & $37.2 \%$ & $6 \quad 14$ & $14.1 \%$ \\
\hline 20 & $19.6 \%$ & 4 & $11.4 \%$ & 0 & 0 & 16 & 2 & 0 & 0 & 0 & 0 & 16 & $4.3 \%$ & 2 & $3.1 \%$ & 36 & $7.6 \%$ & 6 & $6.1 \%$ \\
\hline 0 & $0.0 \%$ & 0 & $0.0 \%$ & 1 & 1 & 2 & 2 & 0 & 0 & 0 & 0 & 2 & $0.5 \%$ & 3 & $4.7 \%$ & 2 & $0.4 \%$ & 3 & $3.0 \%$ \\
\hline 0 & $0.0 \%$ & 0 & $0.0 \%$ & 0 & 0 & 1 & 1 & 0 & 0 & 0 & 0 & 2 & $0.5 \%$ & 1 & $1.6 \%$ & 2 & $0.4 \%$ & 1 & $1.0 \%$ \\
\hline 0 & $0.0 \%$ & 0 & $0.0 \%$ & 0 & 0 & 1 & 1 & 0 & 0 & 0 & 0 & 1 & $0.3 \%$ & 1 & $1.6 \%$ & 1 & $0.2 \%$ & 1 & $1.0 \%$ \\
\hline 1 & $1.0 \%$ & 1 & $2.9 \%$ & 0 & 0 & 1 & 1 & 0 & 0 & 0 & 0 & 1 & $0.3 \%$ & 1 & $1.6 \%$ & 2 & $0.4 \%$ & 2 & $2.0 \%$ \\
\hline 1 & $1.0 \%$ & 1 & $2.9 \%$ & 1 & 1 & 0 & 0 & 0 & 0 & 0 & 0 & 1 & $0.3 \%$ & 1 & $1.6 \%$ & 2 & $0.4 \%$ & 2 & $2.0 \%$ \\
\hline 1 & $1.0 \%$ & 1 & $2.9 \%$ & 0 & 0 & 0 & 0 & 0 & 0 & 0 & 0 & 0 & $0.0 \%$ & 0 & $0.0 \%$ & 1 & $0.2 \%$ & 1 & $1.0 \%$ \\
\hline 0 & $0.0 \%$ & 0 & $0.0 \%$ & 0 & 0 & 5 & 3 & 0 & 0 & 0 & 0 & 5 & $1.4 \%$ & 3 & $4.7 \%$ & 5 & $1.1 \%$ & 3 & $3.0 \%$ \\
\hline 8 & $7.8 \%$ & 4 & $11.4 \%$ & 0 & 0 & 11 & 6 & 0 & 0 & 0 & 0 & 11 & $3.0 \%$ & 6 & $9.4 \%$ & 19 & $4.0 \%$ & 10 & $10.1 \%$ \\
\hline 1 & $1.0 \%$ & 1 & $2.9 \%$ & 0 & 0 & 0 & 0 & 0 & 0 & 0 & 0 & 0 & $0.0 \%$ & 0 & $0.0 \%$ & 1 & $0.2 \%$ & 1 & $1.0 \%$ \\
\hline 0 & $0.0 \%$ & 0 & $0.0 \%$ & 0 & 0 & 1 & 1 & 0 & 0 & 0 & 0 & 1 & $0.3 \%$ & 1 & $1.6 \%$ & 1 & $0.2 \%$ & 1 & $1.0 \%$ \\
\hline 1 & $1.0 \%$ & 1 & $2.9 \%$ & 0 & 0 & 0 & 0 & 0 & 0 & 0 & 0 & 0 & $0.0 \%$ & 0 & $0.0 \%$ & 1 & $0.2 \%$ & 1 & $1.0 \%$ \\
\hline 2 & $2.0 \%$ & 2 & $5.7 \%$ & 0 & 0 & 0 & 0 & 0 & 0 & 0 & 0 & 0 & $0.0 \%$ & 0 & $0.0 \%$ & 2 & $0.4 \%$ & 2 & $2.0 \%$ \\
\hline 10 & $9.8 \%$ & 3 & $8.6 \%$ & 0 & 0 & 5 & 3 & 0 & 0 & 0 & 0 & 5 & $1.4 \%$ & 3 & $4.7 \%$ & 15 & $3.2 \%$ & 6 & $6.1 \%$ \\
\hline 2 & $2.0 \%$ & 2 & $5.7 \%$ & 0 & 0 & 0 & 0 & 0 & 0 & 0 & 0 & 0 & $0.0 \%$ & 0 & $0.0 \%$ & 2 & $0.4 \%$ & 2 & $2.0 \%$ \\
\hline 10 & $9.8 \%$ & 5 & $14.3 \%$ & 2 & 2 & 25 & 11 & 0 & 0 & 1 & 0 & 28 & $7.6 \%$ & 13 & $20.3 \%$ & 38 & $8.1 \%$ & 18 & $18.2 \%$ \\
\hline 102 & 100 & 35 & 100 & 8 & 7 & 338 & 52 & 11 & 2 & 12 & 3 & 369 & 100 & 64 & 100 & 471 & 100 & 99 & 100 \\
\hline
\end{tabular}

